British Journal of Nutrition, Vol. 54, No. 1

Plate 1

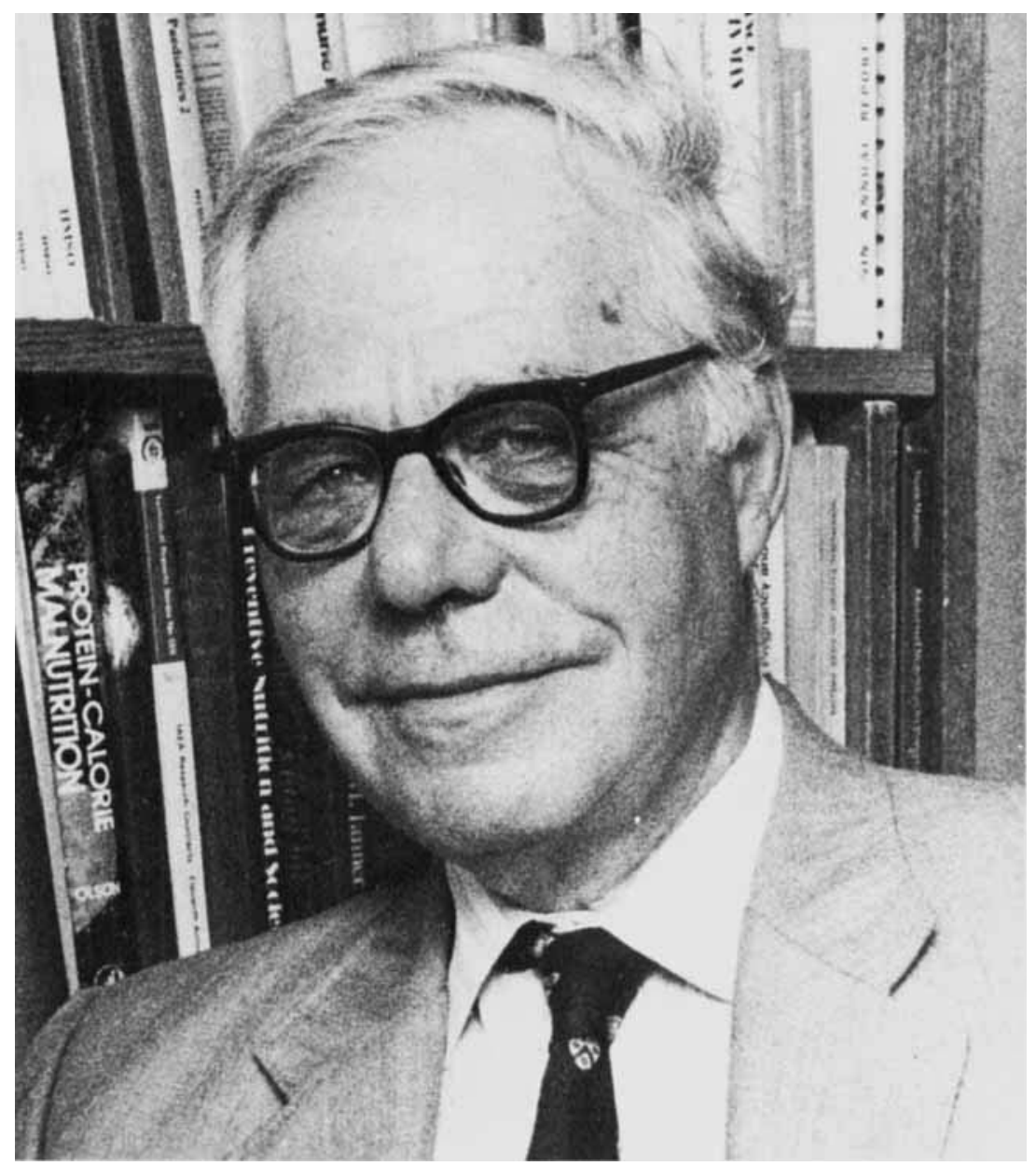

J. C. WATERLOW 


\title{
Welcome to the XIII International Congress of Nutrition
}

\author{
By J. C. WA TER LOW, President of the Nutrition Society
}

The British Journal of Nutrition is the journal of the Nutrition Society which, with the Royal Society, hosts the XIII International Congress of Nutrition. It is appropriate that the Journal should take note of such an important event in the Society's history, as the last international congress in the UK was held in Edinburgh in 1963 and it seems unlikely that there will be another one in this country for perhaps half a century.

Each international congress has its own flavour, derived partly from the milieu and way of life of the host country and partly from the philosophy underlying the selection and organization of the contributions. It is a commonplace to emphasize that nutrition is a very wide subject, both because of the number of different branches of science on which it draws and because it covers such a broad spectrum of activities, ranging from the purely theoretical to the strictly practical.

No programme can fulfil everyone's expectations, and many may feel that we have given too little attention to practical problems, particularly at a time when large numbers of people are facing starvation. At an early stage it was decided that the underlying theme in this congress should be the scientific aspect of nutrition, in particular the need for more scientific knowledge to enable us to solve the practical problems of which we are all well aware. There were several reasons for this choice of emphasis. In human nutrition it is difficult not to feel that, in the world as a whole, we are faced with two completely different sets of problems: those of the developed and those of the developing countries. It is true that the causes of these problems are very different, if by 'causes' one means the economic and social settings in which they arise. No one could deny that in the Third World malnutrition is the result of poverty, whereas the very phrase 'disease of affluence' in industrialized countries emphasizes the role of excess. Nevertheless, in both worlds, lack of scientific knowledge is a constraint on the development of policy for the prevention of nutritionally induced disorders. I think it is an over-simplification to suppose that in the field of nutrition we have the knowledge and all that is needed is the will to apply it.

When it comes to questions of how the body works or fails to work, there are many points of contact between, and of relevance to, the problems of the two worlds. For example, the extent to which the body can adapt its energy metabolism to different levels of intake is of concern to both the hungry and the obese. There is also the fascinating web of inter-relationships between nutrition and cancer to consider.

Another reason for emphasizing the scientific aspect of our subject is that processes common to both human and animal nutrition can best be brought together scientifically. The objectives of research on farm animals and on man are usually different and are frequently pursued in different institutions. This practical separation has had some bad effects, particularly in relation to training which tends to be in the nutrition of farm animals or in the nutrition of man but not both. The Nutrition Society has long recognized this problem and has always tried to bring nutritionists of all complexions together in the planning of its scientific programmes. The British Journal of Nutrition has also played a part in this endeavour by encouraging the publication of papers in all branches of nutrition and from all countries. This congress provides a further opportunity for bridging the gap between these two main fields of activity. 
As I indicated at the beginning, the scientific programme at any congress must be influenced to some extent by the background of research and activity in the host country. Our traditional interest in nutrition has two strands: one is the research arising from the background of physiology and biochemistry developed in this century by pioneers such as Gowland Hopkins and Edward Mellanby, the other is the active interest shown in nutrition by such public bodies as our Research Councils and various government departments who have to deal with practical problems. Here we still feel the influence of that remarkable man Lord Boyd Orr, the first Director-General of FAO.

These two strands, of scientific enquiry and public concern, came together in our country in the post-war years with an increasing awareness of nutritional problems in the Third World. It is not always appreciated how recent this awareness is: for instance, in the year 1935, when Dr Cicely Williams published her first paper on kwashiorkor, the introduction to a leading textbook of nutrition stated that the nutritional problems of the world were well-nigh solved. Things have changed since then, however, and for many members of this Society active exposure to malnutrition in developing countries has been the starting point of their interest in nutrition. We have made every effort to reflect that experience in the programme and to make it a truly international congress.

It is of some interest to look back on the VI International Congress in Edinburgh in 1963 , the last International Congress of Nutrition to be held in the UK. Twenty-two years is nowadays quite a long time in the development of science yet at first sight it might seem that not very much has changed. Our Patron then, as now, was H.R.H. The Duke of Edinburgh; Lord Boyd Orr was the Honorary President, and Sir David Cuthbertson, Director of the Rowett Research Institute, Aberdeen, was President. The President of this congress is Sir Kenneth Blaxter, who succeeded Sir David in that post. This is evidence of the abiding importance of Scotland in the field of British nutrition. It is a pleasure to see, in the programme of the 1963 congress, the names of so many colleagues from all over the world who are still active today.

There were about 1500 registered members of the 1963 congress and we shall be pleased indeed if in 1985 this number proves to be $50 \%$ greater. There are also important differences in organization. In 1963 there were one or two symposia in the mornings and five simultaneous meetings of 'sections' in the afternoons, at which free communications were given. At Brighton there will be many more simultaneous sessions - a system that has both benefits and drawbacks. We hope that it will allow for a higher proportion of active participants in workshops as well as in the more formal symposia and colloquia.

The programme for the Edinburgh congress seems to me to have been very modern in some ways, but with interesting gaps. The topic having the greatest number of sessions was 'Diet and Disease' and, under that heading, the major emphasis was accorded to cardiovascular disease; on the other hand, the subject of obesity was virtually ignored. A considerable amount of attention was given to the problems of developing countries, with important contributions coming from representatives of the United Nations agencies. Some of the subjects not dealt with at that time were nutrition and cancer, nutrition education, and the effects of nutrition on the immune response or on mental and behavioural development. In contrast, there were very forward-looking sessions on plant genetics and on animal production under adverse climatic conditions. My purpose in making this very superficial comparison is to suggest that a systematic analysis of the programmes of successive international congresses, starting with the first, could provide an interesting overview of the world-wide development of our subject.

In 1963 the closing session had the stirring title 'Nutrition as the Servant of Man'. This was re-echoed in the theme of the 4th Asian Congress of Nutrition 20 years later: 'Better 
Nutrition: Better Life'. 'Nutritional Science in the Service of Man' is still our theme in 1985.

Although the UK is the host country for this congress, we are unfortunately not able to cover all the expenses of all our guests, as is expected of a good host. We have done as much as we can towards meeting expenses, through the generous contributions received from industry and even more from the Society's own funds which are supported to a substantial extent by the Journal; thus every person or institution subscribing to the British Journal of Nutrition is making a contribution to this congress. 